\title{
ANALISIS EFISIENSI TEKNIS PENGGUNAAN FAKTOR-FAKTOR PRODUKSI USAHATANI PADI PRA IMPLEMENTASI PERLINDUNGAN LAHAN PANGAN PERTANIAN BERKELANJUTAN \\ (Kasus Petani di Desa Jati Kecamatan Tarogong Kaler Kabupaten Garut Jawa Barat)
}

\author{
W. Nahraeni ${ }^{1 \mathrm{a}}$, S. Masithoh ${ }^{1}$, E. Puspitasari ${ }^{1}$ \\ ${ }^{1}$ Jurusan Agribisnis, Fakultas Pertanian Universitas Djuanda Bogor \\ Jalan Tol Ciawi No. 1 Kotak Pos 35 Bogor 16720 \\ ${ }^{a}$ Korespondensi: Wini Nahraeni. Telp: 08129682305; E-mail: winisivadevi@yahoo.com
}

\begin{abstract}
This study aims to determine the effect of the factors on rice production, the level of technical efficiency and economical efficiency of rice farming. The data collection was conducted from November to December 2015 in the Jati village Tarogong Kaler District Garut regency West Java Province. The data were analyzed using the production function of Cobb-Douglas are processed using SPSS 16.0 applications. The results showed that the variables of land area, number of seeds, labor, experience, status of farmers and extension respectively positive effect on rice production and significant at $\alpha$ level of below 10 percent, except for fertilizer $\mathrm{N}$ and $\mathrm{P}$ fertilizer variable is negative and does not significantly to the rice production of fertilizer $\mathrm{N}$. in the aspect of economic efficiency, rice farming is done in the village of Jati is not efficient, it can be seen from the ratio of NPM / BKM larger or smaller than one. Variable land and seeds have a ratio of NPM / BKM more than one so that variables can still be added in order to be efficient, while the labor force has a ratio of NPM / BKM less than one, so that the input variables can be said to have excess, in order to input these variables efficient then this variable can be reduced. The land has the highest elasticity in increasing rice production values, then Government programs to protect agricultural land from the transfer function through the PLP2B program is very relevant.
\end{abstract}

Keywords: Technical efficiency, Value of Marginal Product, Cobb-Douglas

\begin{abstract}
ABSTRAK
Penelitian ini bertujuan untuk mengetahui pengaruh penggunaan faktor-faktor produksi terhadap produksi padi, tingkat efisiensi teknis dan efisiensi ekonomis usahatani padi. Pengumpulan data dilaksanakan pada November - Desember 2015 di Desa Jati Kecamatan Tarogong Kaler Kabupaten Garut Provinsi Jawa Barat. Data dianalisis menggunakan fungsi produksi Cobb-Douglas yang diolah dengan menggunakan aplikasi SPSS 16.0. Hasil penelitian menunjukkan bahwa variabel luas lahan, jumlah benih, tenaga kerja, pengalaman, status petani serta penyuluhan masing-masing berpengaruh positif terhadap produksi padi dan signifikan pada taraf $\alpha$ dibawah 10 persen, kecuali pupuk $\mathrm{N}$ dan pupuk $\mathrm{P}$. Variabel yang bernilai negatif dan tidak signifikan terhadap produksi padi adalah pupuk N. Pada aspek efisiensi ekonomis, usahatani padi yang dilakukan di Desa Jati belum efisien, hal ini dapat dilihat dari rasio NPM/BKM yang lebih besar atau lebih kecil dari satu. Variabel luas lahan dan benih mempunyai rasio NPM/BKM lebih dari satu sehingga variabel-variabel tersebut masih dapat ditambah agar dapat efisien, sedangkan tenaga kerja mempunyai rasio NPM/BKM kurang dari satu, sehingga input variabel tersebut dapat dikatakan sudah berlebih, agar input variabel ini efisien maka variabel ini dapat dikurangi. Lahan mempunyai elastisitas paling tinggi dalam meningkatkan nilai produksi padi, maka program pemerintah untuk melindungi lahan pertanian dari pengalihan fungsi melalui program PLP2B sangat relevan.
\end{abstract}

Kata kunci : Efisiensi teknik, Nilai Produk Marjinal, Cobb-Douglas 


\section{PENDAHULUAN}

Padi merupakan salah satu komoditas subsektor tanaman pangan yang paling banyak diusahakan oleh petani di Indonesia. Produk turunan padi berupa beras merupakan bahan pangan yang paling banyak dikonsumsi oleh masyarakat Indonesia dibandingkan dengan bahan pangan lainnya. Ketersediaan beras untuk memenuhi kebutuhan masyarakat tergantung pada kemampuan produksi padi nasional. Produksi padi di Indonesia pada tahun 2015 mencapai 75,55 juta ton GKG atau mengalami kenaikan sebanyak 4,70 juta ton $(6,64$ persen) dibandingkan tahun 2014. Kenaikan produksi terjadi karena adanya kenaikan luas panen padi seluas 0,51 juta ha $(3,71$ persen $)$ dan kenaikan produktivitas sebesar $1,45 \mathrm{kuintal} / \mathrm{hektar}$ (2,82 persen) (BPS, 2015). Produktivitas ini masih di bawah standar yang diharapkan oleh pemerintah.

Data Badan Pusat Statistik Jawa Barat (2012) menyebutkan bahwa dibandingkan dengan tahun 2011, pada tahun 2012 telah terjadi penurunan luas tanam sebesar 3.1 persen, luas panen 3,38 persen, produksi 3,38 persen, dan produktivitas 0.81 persen (BPS Jawa Barat, 2012). Penyebab penurunan ini diduga adanya perubahan cuaca dan iklim, tingkat efisiensi faktor yang belum optimal

Permasalahan lainnya adalah adalah banyaknya fenomena alih fungsi lahan sawah yang masih produktif yang apabila berlangsung terus menerus akan mengakibatkan turunnya produksi dan produktivitas. Dengan demikian untuk mengendalikan alih fungsi lahan yang semakin tinggi, pemerintah mengeluarkan UU No 41 tahun 2009 dan di Jawa Barat mengeluarkan PERDA Provinsi Jawa Barat No 27 tahun 2010 tentang 'Perlindungan Lahan Pertanian Pangan Berkelanjutan" (PLP2B) dan cadangannya.

Kusnadi et al (2011) menyatakan bahwa kondisi penurunan produktivitas dapat ditingkatkan melalui intensifikasi atau perbaikan teknologi, karena peningkatan produksi padi melalui ekstensifikasi relatif sulit dilakukan akibat terbatasnya lahan pertanian. Oleh karena itu salah satu upaya peningkatan produksi padi dapat dilakukan melalui efisiensi dengan cara mengoptimalkan penggunaan faktor-faktor produksi secara efisien.

Beberapa penelitian menemukan bahwa petani di negara berkembang belum sepenuhnya mencapai efisiensi teknik karena baru mencapai efisiensi sekitar 60 - 70 persen (Bravo-Ureta et al, 2007; Tinaprilla, 2012 ). Beberapa penelitian efisiensi sudah banyak dilakukan, namun penelitian empiris efisiensi usahatani padi berbasis pra implementasi perlindungan lahan pangan berkelanjutan (PLP2B) belum dilakukan sebelumnya. Oleh karena itu, penelitian peningkatan efisiensi usahatani padi berbasis pra implementasi perlindungan lahan pertanian pangan berkelanjutan, sangat penting untuk dilakukan.

Kecamatan Tarogong Kaler merupakan salah satu wilayah yang menjadi sentra produksi padi di Kabupaten Garut. Ketersediaan lahan yang cukup dan lahan pertanian yang potensial menjadikan kecamatan ini sebagai salah satu daerah yang menerima dan menyetujui program pemerintah PLP2B yang dalam jangka waktu panjang tidak dapat dialihfungsikan. untuk memenuhi dan meningkatkan ketersediaan kebutuhan pangan di Kabupaten Garut.

Penelitian ini bertujuan untuk menganalisis pengaruh penggunaan faktor - faktor produksi terhadap produksi padi sawah pra implementasi PLP2B di Desa Jati Kecamatan Tarogong Kaler dan mengestimasi tingkat efisiensi teknis penggunaan faktor produksi usahatani padi

\section{BAHAN DAN METODE}

\section{Lokasi dan Waktu Penelitian}

Penelitian ini dilaksanakan di Desa Jati, Kecamatan Tarogong Kaler, Kabupaten Garut, Provinsi Jawa Barat. Pemilihan lokasi dilakukan dengan sengaja (purposive) karena wilayah tersebut 
termasuk salah satu kabupaten yang dicanangkan unuk melaksanakan program PLP2B. Pengambilan data berlangsung mulai dari bulan November sampai Desember 2015.

\section{Jenis dan Sumber Data}

Sampel petani yang dipilih adalah para petani yang terdaftar sebagai kelompok tani di Desa Jati Kecamatan Tarogong Kaler Kabupaten yang sebagian lahannya sudah didata oleh pemerintah Kabupaten Garut sebagai penerima program PLP2B khususnya padi. Kemudian sampel ini diambil secara acak dengan menggunakan simple random sampling. Jumlah sampel yang diambil sebanyak 40 petani.

Data yang dikumpulkan meliputi data primer dan data sekunder. Data primer dikumpulkan melalui wawancara langsung dengan petani sampel menggunakan kuisioner. Data sekunder diperoleh dari instansi/lembaga yang berkaitan dengan tujuan penelitian : Dinas Pertanian Kabupaten Garut, BP3K Kecamatan Tarogong Kaler, Kabupaten Garut, Kantor Desa Jati Kecamatan Tarogong Kaler, Kabupaten Garut, Badan Pusat Statistik (BPS) Kabupaten Garut, Jurnal serta sumber-sumber lain yang menunjang.

\section{Metode Analisis Data}

Analisis data yang dilakukan adalah (1) analisis kelayakan usahatani, (2) analisis fungsi produksi Cobb Douglas dan (3) analisis keuntungan maksimum (profit maximization). Perhitungan kelayakan usahatani padi digunakan rumus :

Keuntungan $=\mathrm{TR}-\mathrm{TC}$

dengan :

$\mathrm{TR}=$ Total Revenue (penerimaan total)
$\mathrm{TC} \quad=$ Total Cost $($ biaya total)

$\mathrm{R} / \mathrm{C}$ adalah perbandingan penerimaan total dengan pengeluaran total dari suatu usahatani. Jika nilai R/C usahatani lebih besar dari satu $(\mathrm{R} / \mathrm{C}>1)$ maka usaha tersebut layak untuk diusahakan. Tapi apabila nilai $\mathrm{R} / \mathrm{C}$ usahatani lebih kecil dari satu $(\mathrm{RC}<1)$ maka usahatani tersebut tidak layak diusahakan. Apabila nilai R/C usahatani sama dengan satu maka usaha tani tersebut layak diusahakan tergantung pada pihak yang mengambil keputusan (Soekartawi, 1990). R/C dihitung dengan rumus :

$$
R / C=\frac{\mathrm{TR}}{T C}
$$

Untuk mengetahui factor-faktor yang mempengaruhi produksi padi digunakan fungsi produksi Cobb-Douglas. Selanjutnya untuk menganalisis tingkat efisiensi ekonomis digunakan rasio NPM /BKM. Data yang diperoleh kemudian ditabulasi terlebih dahulu dan diolah dengan menggunakan bantuan komputer dengan program Microsoft Office Excel 2010 dan SPSS 16.0.

\section{Fungsi Produksi Cobb-Douglas}

Model fungsi produksi Cobb Douglas yang digunkan dalam penelitian ini diformulasikan sebagai berikut (Doll dan Orazem, 1978)

$$
\begin{aligned}
& \mathrm{Y}=\mathrm{b}_{0} \mathrm{X}^{\mathrm{b} 1} \mathrm{X}_{2}^{\mathrm{b} 2} \mathrm{X}_{3}^{\mathrm{b} 3} \mathrm{X}_{4}^{\mathrm{b} 4}
\end{aligned}
$$

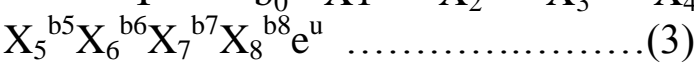

Persamaan (3) selanjutnya diformulasikan ke dalam bentuk linier logaritma, sehingga bentuknya:

$$
\begin{aligned}
& \operatorname{Ln} Y=\ln b_{0}+b_{1} \ln X_{1}+b_{2} \ln X_{2} \\
& +b_{3} \ln X_{3}+b_{4} \ln X_{4}+b_{5} \ln X_{5}+ \\
& b_{6} \ln X_{6}+b_{7} \ln X_{7}+b_{8} \ln X_{8}+u
\end{aligned}
$$

Dengan :

$\mathrm{Y}=$ Produksi padi sawah $(\mathrm{Kg})$

$\mathrm{X}_{1}=$ Luas lahan $(\mathrm{Ha})$

$\mathrm{X}_{2}=$ Jumlah benih $(\mathrm{Kg})$

$\mathrm{X}_{3}=$ Jumlah pupuk $\mathrm{N}(\mathrm{Kg})$

$\mathrm{X}_{4}=$ Jumlah pupuk $\mathrm{P}(\mathrm{Kg})$

$\mathrm{X}_{5}=$ Tenaga kerja $(\mathrm{HOK})$

$\mathrm{X}_{6}=$ Pengalaman berusahatani (tahun)

$\mathrm{X}_{7}=$ Dummy Status petani

$\mathrm{D}=0$, petani penggarap

$\mathrm{D}=1$, pemilik lahan 
$\mathrm{X}_{8}=$ Frekuensi Penyuluhan/produksi

$\mathrm{b}_{0}=$ Intersept $/$ konstanta

$\mathrm{b}_{\mathrm{i}}=$ koefisien parameter penduga, dimana

$\mathrm{i}=1,2,3 \ldots 8$ dengan nilai $\mathrm{b}_{\mathrm{i}}>0$

$\mathrm{u}=$ Unsur sisa (galat)

Koefisien regresi (bi) dari fungsi produksi Cobb Douglass merupakan elastisitas input (ei). Elastisitas produksi (ep) adalah persentase perubahan output sebagai akibat dari persentasi perubahan input, yang dapat diperoleh dengan menjumlahkan elastisitas input ( $\Sigma$ bi). Untuk menghitung alokasi input yang menghasilkan keuntungan maksimum digunakan persamaan:

$$
\mathrm{NPM}=B K M \text { atau } \frac{N P M}{B K M}=1
$$

\section{HASIL DAN PEMBAHASAN}

Karaketristik petani sampel sebagai berikut: umur petani didominasi oleh petani tua sebesar $47,5 \%$, sebagian besar petani berpendidikan SMP dan berpengalaman dalam usahatani padi antara 10-20 tahun, serta jumlah tanggungan keluarga sebagian besar 3-5 jiwa (Tabel 1).

Tabel 1 Karakteristik Petani Sampel di Desa Jati Kecamatan Tarogong Kaler, 2015

\begin{tabular}{|c|c|c|c|c|}
\hline No & & Karakteristik & Jumlah Petani $(\mathrm{n}=40)$ & Persentase $(\%)$ \\
\hline \multirow[t]{5}{*}{1} & Umur & & & \\
\hline & A & 20-34 tahun & 6 & 15 \\
\hline & $\mathrm{B}$ & 35-49 tahun & 12 & 30 \\
\hline & $\mathrm{C}$ & 50-65 tahun & 19 & 47.5 \\
\hline & $\mathrm{D}$ & $>65$ tahun & 3 & 7.5 \\
\hline \multirow[t]{7}{*}{2} & \multicolumn{4}{|c|}{ Pendidikan Formal } \\
\hline & A & Tidak Tamat SD & 4 & 10 \\
\hline & B & Sekolah Dasar & 18 & 45 \\
\hline & $\mathrm{C}$ & SMP/Sederajat & 9 & 22.5 \\
\hline & $\mathrm{D}$ & SMA/Sederajat & 8 & 20 \\
\hline & $\mathrm{E}$ & Diploma & 0 & 0 \\
\hline & $\mathrm{F}$ & Sarjana & 1 & 2.5 \\
\hline \multirow[t]{4}{*}{3} & \multicolumn{4}{|c|}{ Pengalaman Usahatani } \\
\hline & A & $<10$ tahun & 9 & 22.5 \\
\hline & $\mathrm{B}$ & 10-20 tahun & 11 & 27.5 \\
\hline & $\mathrm{C}$ & $>20$ tahun & 20 & 50 \\
\hline \multirow[t]{4}{*}{4} & \multicolumn{4}{|c|}{ Jumlah Tanggungan Keluarga } \\
\hline & A & $<3$ Jiwa & 19 & 47.5 \\
\hline & $\mathrm{B}$ & 3-5 Jiwa & 20 & 50 \\
\hline & $\mathrm{C}$ & $>5$ Jiwa & 1 & 2.5 \\
\hline
\end{tabular}

\section{Analisis Pendapatan Usahatani Padi}

Tabel 2 memperlihatkan data produksi, penerimaan, biaya, pendapatan dan R/C usahatani padi di Kecamatan Tarogong Kaler musim tanam AprilAgustus 2015. Hasil penelitian menunjukkan rata-rata produksi yang dihasilkan sebesar 5.082 ton/ha. Komponen biaya terbesar adalah biaya tenaga kerja, diikuti biaya pupuk Urea, benih, dan pupuk NPK. Berdasarkan hasil kelayakan usaha, diperoleh nilai $\mathrm{R} / \mathrm{C}$ atas biaya variabel sebesar 2, 98 dan $\mathrm{R} / \mathrm{C}$ atas biaya total sebesar 2,98. Hal ini menunjukkan bahwa usahatani padi menguntungkan dan layak diusahakan, dengan Keuntungan sebesar Rp 14.772.508 (atas biaya variabel) dan $\mathrm{Rp}$ 13.256.885 (atas biaya total) 
Tabel 2 Analisis Usahatani Padi Sawah (1 Ha) Musim Tanam Periode April - Agustus 2015 di Desa Jati Kecamatan Tarogong Kaler Kabupaten Garut.

\begin{tabular}{|c|c|c|c|c|}
\hline \multirow[b]{2}{*}{ No } & \multirow[b]{2}{*}{ Uraian } & \multirow{2}{*}{ Jumlah } & Harga & Nilai \\
\hline & & & $(\mathrm{Rp})$ & $(\mathrm{Rp})$ \\
\hline \multirow[t]{2}{*}{1} & Jumlah Produksi (Kg) & $5.082,50$ & $4.375,87$ & $22.240 .359,28$ \\
\hline & Penerimaan Total & & & 22.240.359,28 \\
\hline \multirow[t]{11}{*}{2} & Biaya variabel & & & \\
\hline & a. Benih $(\mathrm{Kg})$ & 39,73 & $8.627,50$ & $342.727,44$ \\
\hline & b. Pupuk (Kg) & & & \\
\hline & . pupuk Urea & 363,63 & $2.062,00$ & $749.794,75$ \\
\hline & pupuk TSP & 58,75 & $2.693,00$ & $158.213,75$ \\
\hline & pupuk $\mathrm{KCl}$ & 23,45 & $2.200,00$ & $51.590,00$ \\
\hline & pupuk ZA & 8,75 & $1.880,00$ & $16.450,00$ \\
\hline & . $\quad$ pupuk NPK & 118,13 & $1.946,50$ & $229.930,31$ \\
\hline & c. Pestisida (Ltr) & 0,43 & $61.775,00$ & $26.254,38$ \\
\hline & d. Tenaga Kerja (HOK) & 347,50 & & $5.892 .890,00$ \\
\hline & Biaya Variabel Total (TVC) & & & $7.467 .850,63$ \\
\hline 3 & Biaya Variabel Rata-rata (AVC) & & & $1.469,33$ \\
\hline \multirow[t]{6}{*}{4} & Biaya Tetap & & & \\
\hline & a. Penyusutan Alat & & & $19.373,33$ \\
\hline & b. Sewa traktor & 3,00 & $135.250,00$ & $405.750,00$ \\
\hline & c. Sewa kerbau (Ekor) & 3,00 & $88.500,00$ & $265.500,00$ \\
\hline & d. Sewa lahan $(\mathrm{Ha})$ & & $825.000,00$ & $825.000,00$ \\
\hline & Biaya Tetap Total (TFC) & & & $1.515 .623,33$ \\
\hline 5 & Biaya Total (TC) & & & 8.983.473,96 \\
\hline 6 & \multicolumn{2}{|l|}{ Pendapatan Atas Biaya Variabel Total } & & 14.772.508,65 \\
\hline 7 & \multicolumn{2}{|l|}{ Pendapatan Atas Biaya Total } & & 13.256.885,32 \\
\hline 8 & \multicolumn{2}{|l|}{ R/C Atas Biaya Variabel Total } & & 2,98 \\
\hline 9 & R/C Atas Biaya Total & & & 2,48 \\
\hline
\end{tabular}

\section{Analisis Fungsi Produksi}

Fungsi produksi menggambarkan suatu hubungan antara faktor-fakor produksi dengan hasil produksinya. Pada pendugaan awal semua variabel dimasukkan kedalam model variabel antara lain variabel luas lahan $\left(\mathrm{X}_{1}\right)$, benih $\left(\mathrm{X}_{2}\right)$, pupuk $\mathrm{N}\left(\mathrm{X}_{3}\right)$, pupuk $\mathrm{P}\left(\mathrm{X}_{4}\right)$, pupuk $\mathrm{K}\left(\mathrm{X}_{5}\right)$, pestisida $\left(\mathrm{X}_{6}\right)$, tenaga keja $\left(\mathrm{X}_{7}\right)$, umur $\left(\mathrm{X}_{8}\right)$, pengalaman $\left(\mathrm{X}_{9}\right)$, status petani $\left(\mathrm{X}_{10}\right)$, dan frekuensi penyuluhan $\left(\mathrm{X}_{11}\right)$, namun setelah dilakukan proses pengongolahan data menggunakan program SPSS 16.0, melihat adanya terdapat beberapa data multikulinier yang muncul, maka sebagian data yang dimasukkan kedalam model dikurangi untuk memperoleh model fungsi produksi Cobb-Douglass yang terbaik. Adapun model yang dihasilkan yaitu menggunakan variabel luas lahan $\left(\mathrm{X}_{1}\right)$, benih $\left(\mathrm{X}_{2}\right)$, pupuk $\mathrm{N}\left(\mathrm{X}_{3}\right)$, pupuk $\mathrm{P}\left(\mathrm{X}_{4}\right)$, tenaga keja $\left(\mathrm{X}_{5}\right)$, pengalaman $\left(\mathrm{X}_{6}\right)$, status petani $\left(\mathrm{X}_{7}\right)$, dan frekuensi penyuluhan $\left(\mathrm{X}_{8}\right)$. 
Tabel 3. Hasil Pendugaan Fungsi Produksi Usahatani Padi di Desa Jati Kecamatan Tarogong Kaler Tahun 2015.

\begin{tabular}{lrrrrr}
\hline \multicolumn{1}{c}{ Model } & \multicolumn{1}{c}{ B } & \multicolumn{1}{c}{ Std. Error } & \multicolumn{1}{c}{ Sig. } & VIF \\
\hline (Constant) & 5.986 & 5.545 & 1.080 & .289 & \\
Luas.lahan & 0.667 & 0.556 & 1.199 & $.067^{*}$ & 8.850 \\
jumlah.benih & 0.143 & 0.284 & 0.503 & $.085^{*}$ & 6.094 \\
Pupuk.N & -0.040 & 0.362 & -0.112 & .145 & 4.584 \\
Pupuk.P & 0.036 & 0.019 & -0.015 & .226 & 1.270 \\
TK & 0.426 & 0.930 & 0.458 & $.014^{* *}$ & 5.938 \\
Pengalaman & 0.029 & 0.116 & -0.248 & $.085^{*}$ & 1.445 \\
Status.petani & 0.032 & 0.410 & -0.078 & $.105^{*}$ & 1.296 \\
Penyuluhan & 0.043 & 0.023 & 1.853 & $.073^{*}$ & 1.756 \\
\hline $\mathrm{R}^{2}$ & \multicolumn{7}{c}{} & & 74,7 \\
F-Hitung & & & & & 8,844 \\
\hline
\end{tabular}

Keterangan : * berpengaruh nyata pada taraf $90 \%(\alpha=0,1)$

**berpengaruh nyata pada taraf $95 \%(\alpha=0,05)$

Tabel 3 menunjukkan hasil pendugaan model fungsi produksi Cobb Douglas. Berdasarkan kriteria ekonomi, semua variabel bertanda positif, kecuali variabel pupuk $\mathrm{N}$ bertanda negatif. Hal ini sesuai dengan hipotesis. Variabel luas lahan, benih, pupuk $\mathrm{P}$, tenaga kerja, pengalaman, status petani dan penyuluhan bertanda positif, sedangkan pupuk $\mathrm{N}$ bernilai negatif. Kriteria statistic dapat dilihat dari nilai $\mathrm{R}^{2}, \mathrm{~F}$ hitung dan $\mathrm{t}$ hitung. Berdasarkan hasil pendugaan diperoleh koefisien determinasi $\left(\mathrm{R}^{2}\right)$ sebesar 74,7 persen. Nilai $\mathrm{R}^{2}$ sebesar 74,7 persen menunjukkan bahwa 74,7 persen dari keragaman produksi padi dapat dijelaskan oleh variabel luas lahan, benih, pupuk $\mathrm{N}$, pupuk $\mathrm{P}$, tenaga kerja, pengalaman bertani, status petani, dan frekuensi penyuluhan. Sisanya, variasi sebesar 25,3 persen dijelaskan oleh faktor lain yang tidak dimasukkan ke dalam model seperti musim tanam, pengaruh iklim, cuaca serta serangan hama dan penyakit. Berdasarkan pendugaan model produksi yang diperoleh pada Tabel 2, terlihat nilai F-hitung sebesar 8,844 > F-Tabel sebesar 2,99 yang signifikan pada taraf kepercayaan 99 persen $(\alpha=0,01)$. Hal ini menunjukkan bahwa faktor-faktor produksi yang digunakan dalam model secara bersamasama berpengaruh nyata terhadap produksi padi. Berdasarkan uji t, terlihat bahwa variabel luas lahan, jumlah benih, pengalaman petani dan intensitas penyuluhan berpengaruh nyata (signifikan pada taraf $\alpha=0,1$ (10\%) sedangkan penggunakan tenaga kerja nyata pada taraf $\alpha=0,05 \quad(5 \%)$. Dua variabel yaitu penggunaan pupuk $\mathrm{N}$ dan $\mathrm{P}$ tidak berpengaruh nyata. Hal ini diduga penggunaan pupuk $\mathrm{N}$ dan $\mathrm{P}$ di daerah penelitian sudah berlebih.

Dalam model fungsi produksi Cobb-Douglas, besaran koefisien regresi merupakan elastisitas produksi dari variabel-variabel tersebut. Berdasarkan Tabel 2, terlihat bahwa luas lahan memiliki elastisitas paling tinggi sebesar 0,667 artinya jika luas lahan ditambah satu persen maka produksi padi akan bertambah 0,667 persen, dengan asumsi faktor-faktor lain dianggap tetap (cateris paribus). Hasil penelitian ini senada dengan penelitian Nahraeni ( 2012), Dumais et al (2012), Kaban (2012), Prahari (2013), dan Rivanda (2014). Besarnya nilai koefisien pada luas lahan menunjukkan bahwa variabel lahan merupakan variabel yang paling berpengaruh terhadap peningkatan produksi padi di daerah penelitian. Namun ,melihat kondisi di lapang yang sudah tidak memungkinkan untuk menambah 
luas lahan yang dapat digunakan untuk produksi padi, menjadikan daerah tersebut layak untuk dipertahankan guna dapat memenuhi kecukupan ketersediaan beras. Besaran elastisitas kedua adalah tenaga kerja $(0,426)$, jumlah benih $(0,143)$, penyuluhan $(0,043)$, pupuk $\mathrm{P}(0,036)$ sedangkan status petani mempunyai nilai elastisitas yang kecil, hal ini dikarenakan status lahan garapan yang digunakan oleh petani merupakan lahan milik orang lain, baik yang berstatus lahan sewa maupun lahan kerjasama dengan sistem bagi hasil.

Berdasarkan Tabel 3, dapat diperoleh persamaan fungsi produksi $C o b b$ Douglas usahatani padi adalah:

$$
\begin{aligned}
\operatorname{Ln} Y= & 5,98+0.667 \operatorname{Ln} X_{1}+0.143 \operatorname{Ln} X_{2} \\
& +(-0.040) \operatorname{Ln} X_{3}+0.036 \operatorname{Ln} X_{4}+ \\
& 0.426 \operatorname{Ln} X_{5}+0.029 \operatorname{Ln} X_{6}+ \\
& 0.032 \operatorname{Ln} X_{7}+0.043 \operatorname{Ln} X_{8}
\end{aligned}
$$

Penjumlahan nilai-nilai elastisitas input dapat digunakan untuk menghitung skala usaha. Model produksi yang diduga menunjukkan bahwa jumlah nilai-nilai parameter penjelas adalah 1,336. Angka tersebut merupakan hasil dari penjumlahan koefisien regresi faktor produksi yang Jumlah nilai elastisitas lebih dari satu menunjukkan bahwa usahatani padi berada pada skala kenaikan hasil yang meningkat (increasing return to scale). Nilai ini mengandung arti bahwa penambahan satu persen dari masing-masing faktor produksi secara bersama-sama akan meningkatkan produksi sebesar 1,336 persen.

\section{KESIMPULAN DAN IMPLIKASI KEBIJAKAN}

\section{Kesimpulan}

1. Peningkatan luas lahan, jumlah benih, tenaga kerja, pengalaman, status petani dan penyuluhan berpengaruh positif dan signifikan mampu meningkatkan produksi padi di daerah penelitian, kecuali variabel pupuk $\mathrm{N}$ dan pupuk $\mathrm{P}$ tidak berpengaruh nyata terhadap produksi padi. Luas lahan mempunyai nilai elastisitas yang paling tinggi sehingga produksi padi sangat responsif terhadap perubahan luas lahan. Nilai elastisitas setelah lahan adalah penggunaan tenaga kerja, benih, dan frekuensi penyuluhan

2. Skala usaha produksi padi berada pada tingkat increasing return to scale (kenaikan hasil bertambah dengan nilai 1,336. Peningkatan factor produksi sebesar $1 \%$ secara bersama sama akan meningkatkan produksi padi lebih besar dari $1 \%$

\section{Implikasi Kebijakan}

1. Berdasarkan hasil analisis, variabel luas lahan berpengaruh nyata dan memiliki nilai elastisitas yang paling tinggi terhadap produksi padi, sehingga lahan yang terdapat di daerah penelitian layak untuk dipertahankan, dilindungi dan diikut sertakan dalam kegiatan program pemerintah PLP2B yang ada di Kabupaten Garut. Dengan demikian program PLP2B menjadi relevan untuk dilaksanakan.

2. Penggunaan pupuk Urea dan NPK, di daerah penelitian sudah berlebihan, sehingga perlu dikurangi agar tidak terjadi penurunan produksi padi.

3. Berdasarkan hasil analisis, frekuensi penyuluhan secara signifikan mempengaruhi produksi padi. Oleh akrena itu sebaiknya para petani ikut aktif dalam berbagai kegiatan penyuluhan dan pendidikan baik formal ataupun non formal yang diadakan oleh pemerintah daerah setempat untuk meningkatkan efisiensi teknis usahatani padi ditingkat petani.

\section{DAFTAR PUSTAKA}

Badan Perencanaan Pembangunan Nasional. 2015. Evaluasi Implementasi Kebijakan Lahan Pertanian Pangan Berkelanjutan 
(LP2B). http://www.bappenas.go.id. Diakses pada 13 Mei 2016.

Badan Pusat Statistik Jawa Barat. 2012. Berita Resmi BPS. Bandung

Badan Pusat Statistik. 2015. Produksi Padi di Indonesia. http://www.bps.go.id. Diakses pada 13 November 2015.

Bravo-Ureta, B, E.., Solıs, D., Moreira, V., Maripani, J., Thiam, A. and Rivas, T. 2007. 'Technical Efficiency in Farming: A Meta-Regression Analysis', Journal of Productivity Analysis, Vol. 27, (2007) pp. 57-72

Dinas Pertanian Tanaman Pangan. 2015. Data Luas Panen, Produksi, dan Produktivitas Padi di Jawa Barat. http://www.diperta.jabarprov.go.id. Diakses pada 25 Desember 2015.

Dumais, Sudarti, Suzana. 2011. Analisis Efisiensi Penggunaan Faktor Produksi Pada Usahatani Padi Sawah di Desa Mopuya Utara Kecamatan Dumoga Utara Kabupaten Bolaang Mongondow. Journal Agribisnis : 38-47.

Doll Pj, Orazem F. 1978. Production Economics Theory With Applications Second Edition. Canada : John Wiley and sons, Inc.

Kaban. 2012. Analisis Efisiensi Penggunaan Faktor Produksi Pada Usahatani Padi Sawah di Desa Sei Belutu Kecamatan Sei Bamban Kabupaten Serdang Bedagai.
[Skripsi]. Universitas Sumatera Utara. Medan

Kusnadi, N., Tinaprilla, N, Susilowati S.H, Purwoto, A.. 2011. Analisis Usahatani Padi di Beberapa Sentra Produksi Padi di Indonesia. Jurnal Agro Ekonomi Volume 29 No 1, Mei 2011: 25-48.

Prahari B. 2013. Analisis Efisiensi Penggunaan Faktor-Faktor Produksi Usahatani Kubis (Brassica Oleracea) di Kecamatan Kertasari Kabupaten Bandung Provinsi Jawa Barat. [Skripsi]. Universitas Djuanda Bogor. Bogor.

Rivanda D. R. 2014. Analisis Efesiensi Teknis Usahatani Padi Sawah (Pendekatan Stochastic Frontier) Kasus Petani SL-PTT di Kecamatan Telagasari Kabupaten Karawang Provinsi Jawa Barat. [Skripsi]. Universitas Djuanda Bogor. Bogor.

Soekartawi. 1990. Teori Ekonomi Produksi Dengan Pokok Bahasan Analisis Fungsi Produksi CobbDouglas. Jakarta : CV Rajawali

Tinaprilla, N. 2012. Efisiensi Usahatani Padi Antar Wilayah Sentra Produksi di Indonesia; Pendekatan Stochastic Meta Frontier Production Function. Sekolah Pascasarjana Institut Pertanian Bogor. 